\title{
Tear secretion and tear film function in insulin dependent diabetics
}

\author{
Martin Goebbels
}

\begin{abstract}
Background-Diabetic patients often complain of dry eye symptoms, such as burning and/or foreign body sensation. The aim of the present study was to investigate whether diabetes mellitus is correlated with tear film dysfunction and/or tear hyposecretion.

Methods-In 86 consecutive insulin dependent diabetics with retinopathy and 84 non-diabetic controls (age and sex matched) we performed fluorophotometry of tear secretion, the Schirmer test, and impression cytology of the conjunctival epithelium and determined the tear film break up time.

Results-When compared with the healthy control group diabetics showed decreased Schirmer test readings $(-37 \%$, $p<0.001$ ) and significantly more frequent and pronounced signs of conjunctival metaplasia. None of the other values differed between groups.

Conclusion-In insulin dependent diabetics, reflex tearing was demonstrated to be significantly decreased. In contrast, unstimulated basal tear flow and tear film break up time were found to be normal. However, a majority of insulin dependent diabetics shows distinct signs of conjunctival surface disease.
\end{abstract}

(Br f Ophthalmol 2000;84:19-21)

As a systemic disease, diabetes mellitus affects the eyes in many ways-diabetic retinopathy, neovascular glaucoma, cataract, refractory deviations, ptosis, palsy of the oculomotorius nerve, and hordeolosis are typical ocular complications in diabetic patients.

In addition, many diabetic patients complain

University Eye

Hospital, Bonn,

Germany

M Goebbels

Correspondence to: Ringstrasse 21, 52134

Herzogenrath, Germany

Accepted for publication 18 August 1999

Table 1 Tear secretion and tear film function

\begin{tabular}{llll}
\hline & $\begin{array}{l}\text { Patients } \\
\text { Mean }\end{array}$ & Controlst \\
& Mean $(S D)$ & p Value $\neq$ \\
\hline Tear flow $(\mu 1 / \mathrm{min})$ & $1.1(0.4)$ & $1.2(0.5)$ & 0.7 \\
Break up time $(\mathrm{s})$ & $18(10)$ & $16(11)$ & 0.6 \\
Dry eye symptoms $\$(\%)$ & 33 & 26 & - \\
Schirmer test $(\mathrm{mm} / 5 \mathrm{~min})$ & $10(3)$ & $18(5)$ & $<0.001$ \\
\hline
\end{tabular}

*IDDM patients, $\mathrm{n}=86$.

†Healthy controls, $\mathrm{n}=84$

$\ddagger$ Student's $t$ test between patients and controls.

§See text. patients. In the present study, we investigated the amount of tear production, the stability of the tear film and the condition of the conjunctival surface in both diabetic and non-diabetic individuals in order to detect possible tear film anomalies in diabetic patients.

\section{Patients and methods}

We compared 86 consecutive insulin dependent diabetics (age 58 (SD 8) years) with an age and sex matched group of 84 consecutive nondiabetic controls (age 60 (9) years).

Inclusion criteria for the diabetic group were considered: (1) insulin dependency over a period of at least 8 years; (2) onset of diabetes mellitus $>30$ years; (3) diabetic retinopathy without retinal neovascularisation as assessed by clinical evaluation and fluorescein angiography (mild $(n=36)$, moderate $(n=37)$, and severe $(n=13)$ non-proliferative retinopathy according to the Early Treatment Diabetic Retinopathy Study Group). ${ }^{1}$

Exclusion criteria were considered for both groups: (1) topical medication within the past 6 months; (2) a history of laser treatment or other ophthalmic surgical procedures; (3) eye diseases other than dry eye disease (and diabetic retinopathy as for the diabetic group); (4) systemic diseases as assessed by history and clinical evaluation (other than diabetes mellitus as for the diabetic group).

We performed (1) computerised objective fluorophotometry of tear secretion according to a technique described earlier ${ }^{2-4}$; (2) the Schirmer test (without topical anaesthesia); (3) measurement of tear film break up time (after instillation of $1 \mu \mathrm{l} 5 \%$ unpreserved sodium fluorescein), and (4) impression cytology of the conjunctival surface at the 3,6,9, and 12 hour position. The impression cytological specimens were evaluated according to Tseng ${ }^{5}$ in a masked fashion. All diabetic and non-diabetic individuals were asked if they had any dry eye complaints (burning and/or foreign body sensation) according to a standardised questionnaire.

\section{Results}

There were no significant differences between diabetics and non-diabetic controls regarding the amount of aqueous tear flow as assessed by fluorophotometry (diabetics 1.1 (SD 0.4 ) $\mu \mathrm{l} /$ minute; non-diabetics $1.2(0.5) \mu \mathrm{l} /$ minute; $\mathrm{p}$ 0.7; Student's $t$ test; Table 1 ) and the break up time of the tear film (diabetics 18 (10) seconds; non-diabetics 16 (11) seconds; p 0.6; Student's $t$ test; Table 1). Both variables were found to be in a normal range both in the diabetic group and in the non-diabetic control group..$^{2-4} 6$ 


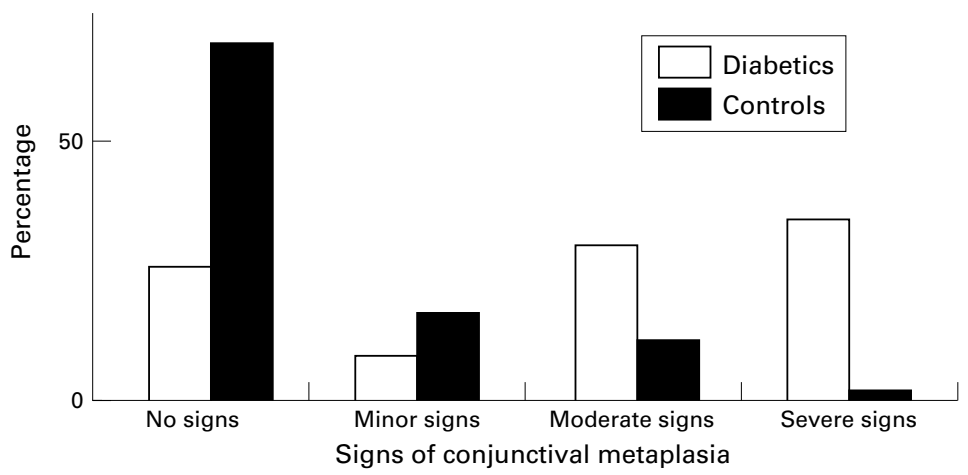

Figure 1 Impression cytological findings (evaluated according to Tseng ${ }^{5}$ ) in diabetics and non-diabetic controls. I: no conjunctival metaplasia; II: minor signs of conjunctival metaplasia; III: moderate conjunctival metaplasia; IV: severe conjunctival metaplasia.

Moreover, in both groups almost the same proportion of subjects complained of dry eye symptoms (at least moderate dry eye complaints according to the scale of the standardised questionnaire): diabetics 28 of 86 ; nondiabetics 22 of 84 ; Table 1 ).

However, Schirmer test values were found to be significantly decreased in the diabetic group when compared with the non-diabetic control group (10 (3) mm/5 minutes; non-diabetics 18 (5) $\mathrm{mm} / 5$ minutes; $\mathrm{p} 0.001$; Table 1 ).

In addition, the diabetic individuals showed significantly more frequent and more pronounced signs of conjunctival metaplasia as assessed by impression cytology (diabetics: no signs of conjunctival metaplasia, 22 of 86 ; minor signs, eight of 86 ; moderate signs, 26 of 86; severe signs, 30 of 86: non-diabetics: no signs, 58 of 84 ; minor signs, 14 of 84 ; moderate signs, 10 of 84; severe signs, two of 84 ; Fig 1 ).

\section{Discussion}

Tear film stability was found to be to be equivalent in diabetic and non-diabetic individuals. However, the measurement of the break up time of the tear film (as assessed by measuring the time interval between a complete blinking and the formation of dry spots in a fluorescein stained tear film) is a very rough test for the determination of tear film stability. Large interindividual and intraindividual deviations can be found even when performed in a standardised procedure. ${ }^{67}$ Thus, even though no significant differences were found between diabetic and non-diabetic subjects regarding tear film break up time, it cannot be concluded definitively from these data that tear film stability does not actually differ between diabetics and non-diabetics.

The amount of aqueous tear secretion as measured by fluorophotometry did not differ between diabetic and non-diabetic individuals. Computerised objective fluorophotometry has been proved to be a reliable tool for the determination of physiological unstimulated tear flow. $^{2-4}$ The intraindividual reproducibility of this technique was shown to be as low as $6 \%$. Thus, the results of this study suggest that the unstimulated aqueous tear flow of diabetics is indeed about the same as that of non-diabetic individuals of the same age and sex. The present data confirm the results obtained by an earlier fluorophotometric study determining the basal tear turnover rates of diabetic and non-diabetic individuals showing no difference between both groups. ${ }^{8}$

Schirmer test values were found to be significantly lower in diabetics than in nondiabetic subjects. Undoubtedly, the Schirmer test is rather a rough screening test for the detection of tear hyposecretion than a technique for the precise measurement of tear production. The sensitivity of the Schirmer test could be shown to be as low as $10-30 \% .{ }^{9-11}$ On the other hand, when performed in a standardised procedure, the finding of a statistically significant difference between the Schirmer test values of two groups may provide valuable information on the amount of stimulated tear secretion. Thus, the present data suggest that on average the amount of provoked reflex tearing is lower in diabetics than in non-diabetic individuals. It is possible that the decreased amount of reflex tearing in diabetics may be the result of a diminished corneal and conjunctival sensitivity, which has been demonstrated in diabetics by electronic aesthesiometry. ${ }^{12}$ In a previous fluorophotometric study Stolwijk et al demonstrated a decreased corneal epithelial stability in diabetics after provocation with eye drops containing oxybuprocaine $0.4 \%$ and $0.01 \%$ benzalkonium chloride, a finding that could be related to the reduced reflex tearing in diabetics. ${ }^{13}$

Impression cytology of the conjunctival surface showed distinctly more frequent and more pronounced signs of conjunctival metaplasia in diabetics. Several reasons could be responsible for this finding: (1) Even though the "basic" unstimulated tear flow is normal in diabetics, the decrease in reflex tearing could be sufficient to induce chronic damage of the conjunctival surface, resulting in conjunctival metaplasia. (2) The trophic function of the tear film (vitamin A, vitamin A carrier, epithelial growth factors, etc) could be disturbed in diabetics, leading to chronic trophic damage of the conjunctival surface. (3) The ocular surface changes found in diabetics could at least partially be the result of a primary surface disease or of metabolic alterations of the conjunctival epithelial cells independent of tear film abnormalities. Both functional and morphological changes have already been demonstrated in the corneal epithelium of diabetics (for example, decreased mechanical stability, breakdown of the corneal epithelial diffusion barrier). ${ }^{13-16}$

In summary, the majority of insulin dependent diabetics show distinct signs of conjunctival surface disease, although basal tear flow and tear film break up time were found to be normal.

\footnotetext{
1 Early Treatment Diabetic Retinopathy Study Group. Early treatment diabetic retinopathy study design and baseline patients characteristics. Ophthalmology 1991;98:741-56.

2 Göbbels M, Achten C, Spitznas M. Effect of topically applied oxymetazoline on tear volume and tear flow in humans. Graefes Arch Clin Exp Ophthalmol 1991;229:1479.

3 Göbbels M, Selbach J, Spitznas M. Effect of eledoisin on tear volume and tear flow in humans as assessed by fluorophotometry. Graefes Arch Clin Exp Ophthalmol 1991;229: 549-52.
} 
4 Göbbels M, Goebels G, Breitbach R, et al. Tear secretion in dry eyes as assessed by objective fluorophotometry. Ger $\mathcal{F}$

5 Tseng S. Staging of conjunctival squamous metaplasia by impression cytology. Ophthalmology 1985;92:728-33.

6 Norn MS. Desiccation of the precoreal tear film. I. Corneal wetting time. Acta Ophthalmol 1969;47:865-9.

7 Vanley GT. Interpretation of tear film break-up. Arch Ophthalmol 1977;95:445-8.

8 Stolwijk TR, van Best JA, Lemkes HH, et al. Determination of basal tear turnover in insulin-dependent diabetes mellitus patients by fluorophotometry. Int Ophthalmol 1991;15 377-82.

9 Lamberts DW, Foster CS, Perry D. Schirmer test after topi$\mathrm{cal}$ anesthesia and the tear meniscus height in normal eyes. Arch Ophthalmol 1979; 97:1082-5.

10 Shapiro A, Merin S. Schirmer test and break-up time of tear film in normal subjects. Am f Ophthalmol 1979;88:752-7. 11 Mackie IA, Seal DV. The questionable dry eye. $\mathrm{Br} f$

12 Draeger J. Corneal sensitivity. Measurement and clinical importance. Heidelberg: Springer, 1984:58-65.

13 Stolwijk ThR, van Best JA, Boot JP, et al. Corneal epithelial barrier function after oxybuprocaine provocation in diabetics. Invest Ophthalmol Vis Sci 1990;31:436-9.

14 Göbbels M, Spitznas M, Oldendoerp J. Impairment of corneal epithelial barrier function in diabetics. Graefes Arch Clin Exp Ophthalmol 1989;227:142-4.

15 Foulks GN, Thoft RA, Perry HD, et al. Factors related to corneal epithelial complications after closed vitrectomy in diabetics. Arch Ophthalmol 1979;97:1076-8.

16 Azar DT, Spurr-Michaud SJ, Tisdale AS, et al. Altered epithelial-basement membrane interactions in diabetic corneas. Arch Ophthalmol 1992;110:537-40. 